\title{
Extranodal B Cell Lymphoma Spreading from Skin to Oral Cavity
}

\author{
Anirudh Kaul, Parmod Kalsotra
}

\begin{abstract}
Non-Hodgkin's lymphoma (NHL) belongs to a group of lymphoid neoplasms that is diverse in manner of presentation, response to therapy and prognosis. Usually oral manifestations of $\mathrm{NHL}$ are secondary to a more widespread involvement throughout the body. Though primary intraoral lesions in NHL are uncommon, it is important to be aware of them, since intraoral manifestations are the presenting symptoms in these patients. ${ }^{2}$ A 58-year-old man presented to our Department with swelling in the vestibule of mouth. CT scan revealed a mass on upper gingival without any bony involvement. Incisional biopsy of the lesion showed diffuse large B cell lymphoma. The patient was treated successfully with chemotherapy. One year after complete remission, patient developed recurrence of primary tumor for which patient was again given chemotherapy treatment but had no significant benefit and succumb to the disease.
\end{abstract}

Keywords: Non-Hodgkin's lymphoma, Extranodal presentation, Vestibule, Gingiva, Incisional biopsy, Chemotherapy.

How to cite this article: Kaul A, Kalsotra P. Extranodal B Cell Lymphoma Spreading from Skin to Oral Cavity. Int J Head Neck Surg 2013;4(3):126-128.

\section{Source of support: Nil}

Conflict of interest: None declared

\section{INTRODUCTION}

Non-Hodgkin lymphoma (NHL) comprises a heterogeneous group of lymphoid neoplasm with a spectrum of behavior ranging from relatively indolent to highly aggressive and potentially fatal. ${ }^{1}$ Only extranodal presentation of Hodgkin's disease is rare while among the NHL's, extranodal presentations are relatively common. Typical locations for extranodal NHLs are the stomach, bowel, lung, orbital tissue, sinuses, thyroid, tonsil, salivary glands, breast, testis and kidney. Waldeyer's ring is mainly second to the gastrointestinal tract in the incidence of extranodal NHL, but primary lymphomas of the oral cavity are uncommon. The oral cavity, including the palate, gingiva, tongue, buccal mucosa, floor of the mouth and lips, is the primary site of extranodal lymphomas in approximately $2 \%$ of cases. ${ }^{5}$

Nonimmunosuppressed patients of any age can be affected, however, most patients are middle-aged to older adults, with male preponderance. In the group of HIV-infected individuals, patients with lymphoma are almost all men, who are overall younger. ${ }^{3}$ Patients generally complain of localized or diffuse soft tissue swelling, pain, mucosal ulceration or discoloration, paresthesias, anesthesia, and loosening of teeth. ${ }^{4}$ Among nonimmunosuppressed patients, the most common type is diffuse large B-cell lymphoma, but mantle cell lymphoma, marginal zone B-cell lymphoma, Burkitt's lymphoma-lymphomablastic lymphoma, peripheral T-cell lymphoma and anaplastic large celllymphoma arealsoreported. ${ }^{4}$

Oral NHL lesions may develop in the soft tissues or centrally within the jaws, with or without nodal or marrow involvement. They appear as nontender swellings commonly affecting the vestibule, gingival or palatal mucosa and clinically the lesion may mimic inflammatory process.

The most widely used system for staging lymphomas is the Ann Arbor classification, initially introduced for Hodgkin's lymphoma and later adopted to classify NHL. Stage I comprise lymphomas localized and confined to one side of the diaphragm with a single lesion, stage IE indicates a single extra lymphatic organ or site involved. Stage II implies the presence of two or more sites of involvement on the same site of diaphragm; stage IIE the localized involvement of an extra lymphatic organ or site. Stage III indicates involvement of multiple lymph nodes on both sides of the diaphragm, including involvement of spleen or localized involvement of an extra lymphatic site. Stage IV is diffuse or disseminated involvement that may include one or more extra lymphatic organism other than spleen (i.e. liver or bone marrow).

The prognosis generally worsens as the disease stage increases. Prognosis is influenced by histologic grade as well, thus large cell lymphomas are concerned as aggressive and have a poor prognosis, whereas the follicular, small cell cleaved type are considered low grade, with good prognosis. ${ }^{10}$

\section{CASE REPORT}

A male patient of 58 years presented to the Department of ENT with complaint of swelling upper gingiva for past 6 days (Fig. 1A). The gingival lesion appeared as an erythematous nodular mass, inflamed but without ulceration, associated with a nonvital tooth with a history of trauma to this area. In addition, the patient had multiple swelling over back and extremeties for past 6 months and skin lesions which were asymptomatic, multiple, papulonodular, shining, smooth, raised, nontender, variable sized over trunk and limbs (Fig. 1B). Lesions associated with bilateral axillary lymph adenopathy (multiple, discrete and mobile). Prior to development of gingival swelling patient had developed excruciating toothache resistant to all drugs. The panoramic 
film showed no bone abnormalities. The general dentist applied endodentic treatment to the nonvital tooth. When the patient was seen for the follow-up 2 weeks after his initial appointment the swelling had increased.

An incisional biopsy was performed and diagnosis of diffuse large B cell lymphoma was rendered. The medical evaluation of this patient revealed chronic hepatitis $\mathrm{C}$ virus (HCV), patient's complete blood count was normal. Also the routine laboratory tests, chest radiograph and bone marrow were normal. The diagnosis was established through histological examination of biopsy tissue coupled with immunohistochemistry, which included CD20, CD10, CD3, CD30, ALK-1 and Ki67. The biopsy specimen was found to be positive for $\mathrm{CD} 20$ and Ki67 and negative for CD3, CD10, CD30, ALK-1and consequently diagnosis of diffuse largeB cell lymphoma was made.

Patient was given six cycles of chemotherapy and was clinically cured (Figs 2A and B). On follow-up subsequent manifestation of $\mathrm{B}$ cell lymphoma in soft tissue vestibule of the maxilla was detected 1 year later after clinically complete remission and was considered to be a recurrence. The morphological characteristics of the second biopsy specimen were identical to those of the first specimen. The patient was treated for recurrence with chemotherapy followed by radiotherapy, and the patient did well for 5 months but died 2 years after the initial diagnosis.

The present case was high grade diffuse large B cell type lymphoma as indicated in the REAL classification, and the clinical stage was IIE with soft tissue involvement; with grave prognosis. The present case is reported because of rare clinical presentation and diagnosis.

\section{DISCUSSION}

Clinical, microscopic, immunohistochemical and molecular features of the reported case confirm the diagnosis of primary diffuse large B cell lymphoma of the oral cavity. Following squamous cell carcinoma, lymphomas are the second most common neoplasm of the head and neck. ${ }^{8}$ Nevertheless the etiology of DLBCL remains unknown. They may originate de novo or represent progression from a less aggressive
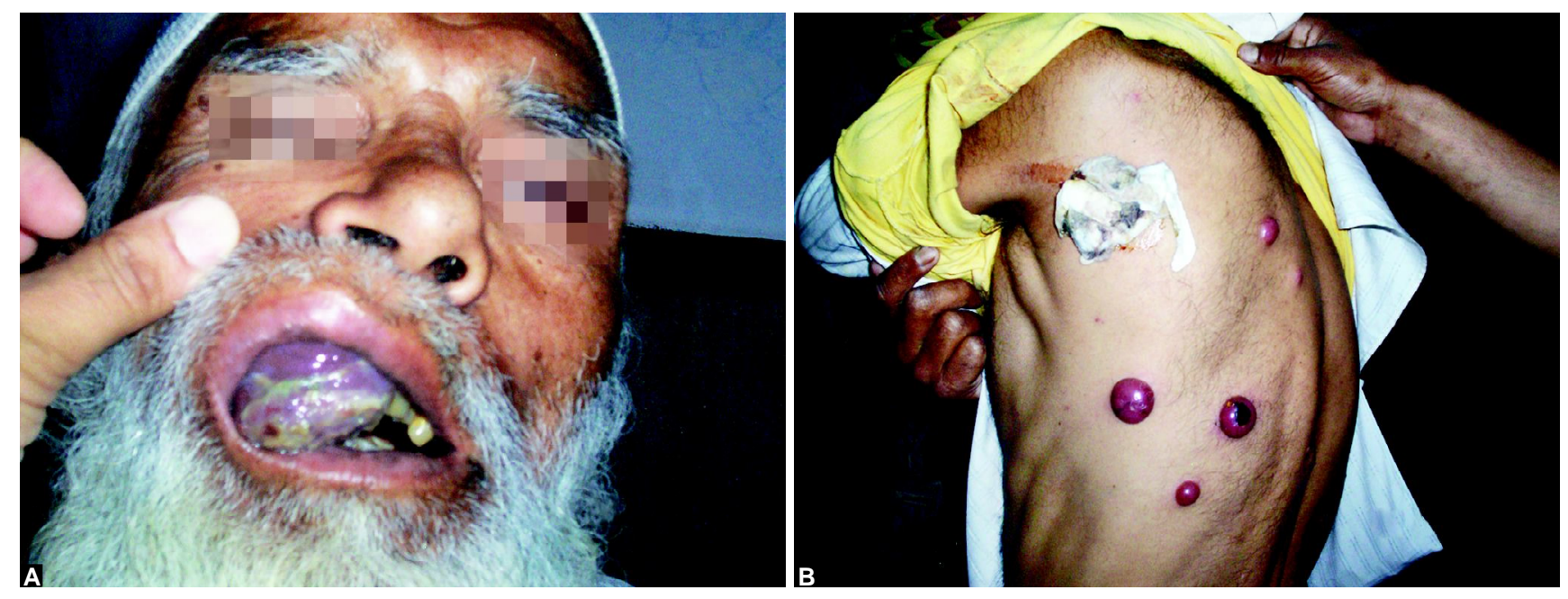

Figs 1A and B: Patient with tumor in vestibule of oral cavity and skin respectively, at the time of presentation
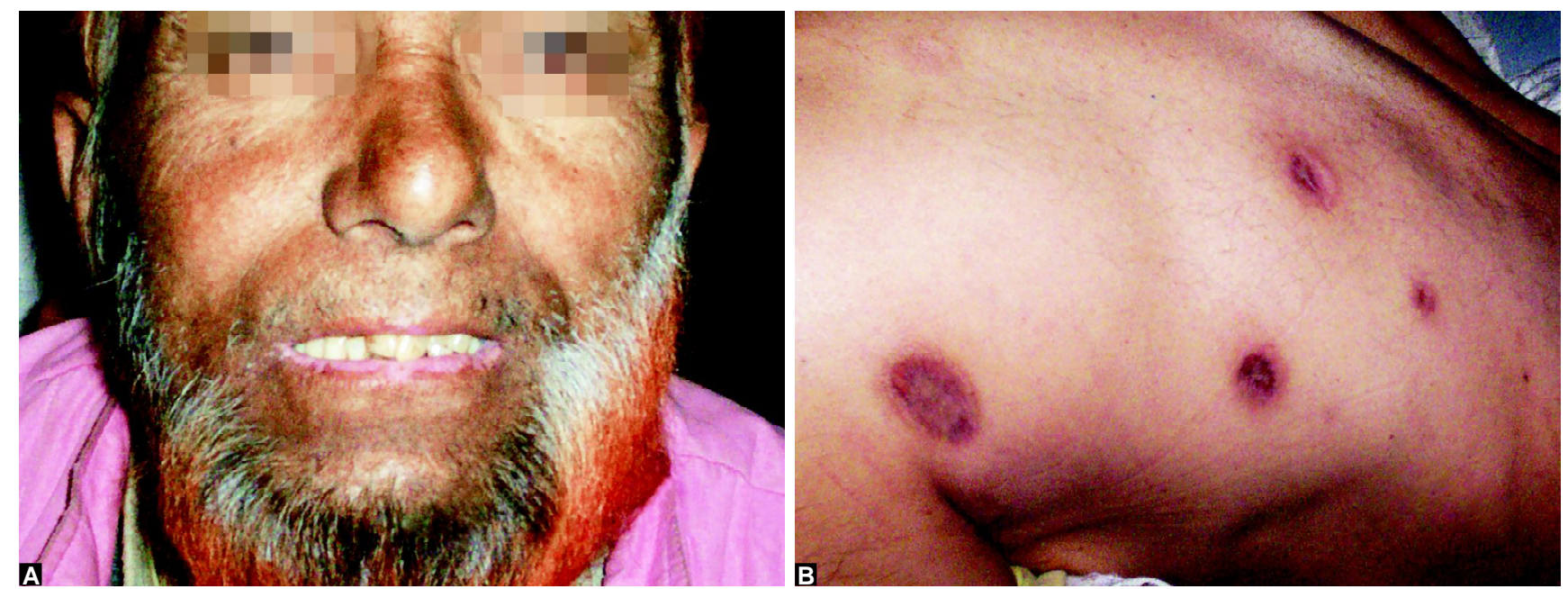

Figs 2A and B: Patient at the completion of treatment viz chemotherapy 
lymphoma, such as follicular lymphoma or small lymphocytic lymphoma. Underlying immunodeficiency is a significant risk factor, and DLBCL in the setting of immunodeficiency is more often Epstein-Barr virus-positive than sporadic DLBCL. 6,7

The concomitant HCV infection is of interest in this case. Recent epidemiological studies have revealed an association between $\mathrm{HCV}$ infection and the clonal proliferation of B-cells. It has been suggested that chronic antigenic stimulation (related to Epstein-Barr virus, HIV, human leukemia lymphoma virus, human herpes virus ${ }^{8}$ or hepatitis viruses $\mathrm{B}, \mathrm{C}$ and $\mathrm{G}$ ) acts on multiple $\mathrm{B}$-cell clones, which may synchronously or metachronously undergo neoplastic transformation. In particular, B-cell lymphoma has been reported to be frequently associated with or related to HCV infection. ${ }^{9}$

Several studies have indicated that a second occurrence after a short period of time ( $<2-3$ years), presenting the same histological properties as the primary lymphoma, should be considered a recurrence of the primary tumor, whereas different histopathology and longer time before recurrence are more indicative of a second primary lymphoma.

Prognosis is influenced by clinical staging and histological grade. Large cell lymphomas are considered aggressive and have a poor prognosis. It is reported that diffuse large cell types of NHL are considered high grade, with a 5-year survival of about $30 \%$, whereas the follicular, small cleaved cell type are considered low grade, with a 5 years survival rate of $70 \%$.

\section{REFERENCES}

1. Salhany KE, Pietra GG. Extranodal lymphoid disorders. Am J Clin Pathol 1993;99:472-85.

2. Ferry JA, Harris NL. Lymphomas and lymphoid hyperplasia in head and neck sites. In: Pilch BZ (Ed). Head Neck Surg Pathol 2001;476-533.
3. Parrington SJ, Punnia-Moorthy A. Primary non-Hodgkin's lymphoma of the mandible presenting following tooth extraction. Brit Dent J 1999;187:468-70.

4. Hicks MJ, Flaitz CM. External root resorption of a primary molar: Incidental histopathological finding of clinical significance Oral Surg Oral Med Oral Pathol Oral Radiol Endod 2001;92:4-8.

5. Kobler P, Borcic J, Filipovic Zore I, Nola M, Sertic D. Primary non-Hodgkin's lymphoma of the oral cavity. Oral Oncol Extra 2005 Jan;41(1):12-14. Available from: http://dx.doi.org/ 10.1016/j.ooe.2004.10.002.

6. Duarte ECB, et al. Plasmablastic lymphoma of oral mucosal type: A case report. Oral Oncol Extra V 2005;41(6):121-24.

7. Jaffe ES, et al. World Health Organization classification of tumors. Pathology and genetics of tumors of haematopoietic and lymphoid tissues. Lyon, France 2001 IARC Press.

8. Kolokotronis A, et al. Localized B-cell non-Hodgkin's lymphoma of oral cavity and maxillofacial region: A clinical study. Oral Surg Oral Med Oral Pathol Oral Radiol Endod 2005;99(3): 303-10.

9. Negri E, Little D, Boiocchi M, La Vecchia C, Franceschi S. B-cell non-Hodgkin's lymphoma and hepatitis $\mathrm{C}$ virus infection: A systematic review. Int J Cancer 2004 Aug10;111(1):1-8.

10. Harris NL, Jaffe ES, Stein H, Banks PM, Chan JK, Cleary ML, et al. A revised European American classification of lymphoid neoplasms: A proposal from the international study lymphoma group. Blood 1994;84:1361-92.

11. Ramani P, Shaheen A, Janaki VR. Primary extranodal non Hodgkin's lymphoma of the oral cavity. Indian J Dermatol Venereol Leprol 2008;70:172-74.

\section{ABOUT THE AUTHORS}

\section{Anirudh Kaul (Corresponding Author)}

Registrar, Department of ENT, Government Medical College, Jammu Jammu and Kashmir, India, e-mail: doctoranirudhkaul@ hotmail.com

\section{Parmod Kalsotra}

Professor, Department of ENT, Head and Neck Surgery, Government Medical College, Jammu, Jammu and Kashmir, India 